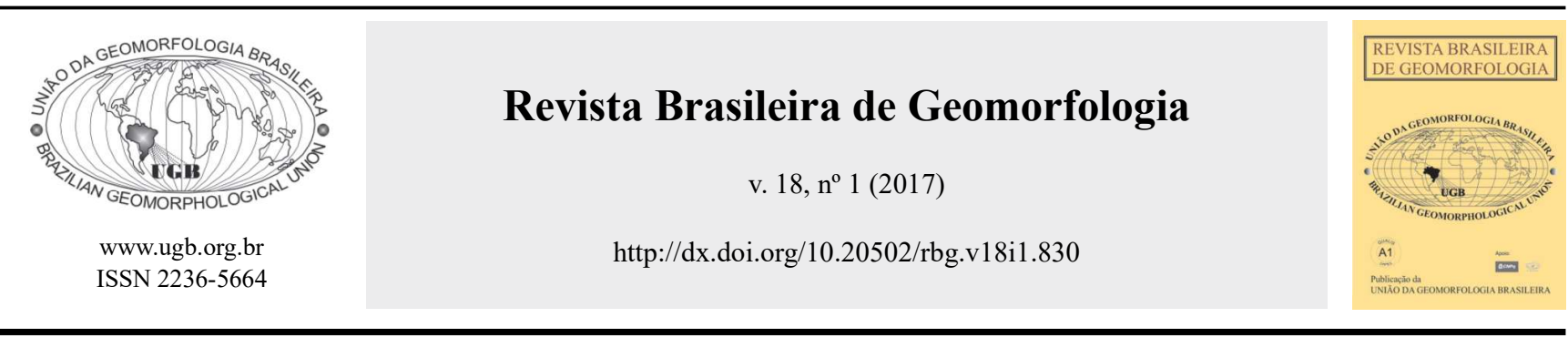

\title{
A MECÂNICA DO TRANSPORTE DE SEDIMENTOS EM SUSPENSÃO NO ESTUÁRIO DO RIO MACUSE, MOÇAMBIQUE, SUDESTE DE ÁFRICA
}

\section{THE MECHANICS OF TRANSPORT OF SEDIMENTS IN SUSPENSION IN MACUSE ESTUARY RIVER, MOZAMBIQUE, SOUTHEAST AFRICA}

\author{
Lucas Lavo António Jimo Miguel \\ Museu Nacional, Universidade Federal do Rio de Janeiro \\ Quinta da Boa Vista, Rio de Janeiro, Rio de Janeiro, CEP: 20.940-040, Brasil \\ Email: lucaslavomiguel@yahoo.com.br \\ Fialho Paloge Juma Nehama \\ Escola Superior de Ciências Marinhas e Costeiras, Universidade Eduardo Mondlane \\ Av. do Zimbábwe, Maputo, CEP: 4660, Moçambique \\ Email: fialho.nehama@gmail.com \\ João Wagner Alencar Castro \\ Museu Nacional, Universidade Federal do Rio de Janeiro \\ Quinta da Boa Vista, Rio de Janeiro, Rio de Janeiro, CEP: 20.940-040, Brasil \\ Email: jwalencastro@mn.ufrj.br
}

\section{Informações sobre o Artigo}

Recebido (Received):

04/09/2016

Aceito (Accepted):

03/03/2017

Palavras-chave:

Hidrodinâmica Estuarina;

Estuário do Rio Macuse; Modelo ELCOM-CAEDYM; Transporte de Sedimentos Suspensos.

\section{Keywords:}

Estuarine hydrodynamics; Estuary of Macuse River; ELCOM-CAEDYM; Transport of Suspended Sediments.

\section{Resumo:}

O presente manuscrito estuda a mecânica do transporte de sedimentos em suspensão no estuário do Rio Macuse em Moçambique, costa sudeste Africana. Os procedimentos metodológicos basearam-se em levantamentos geomorfológicos e oceanográficos realizados em 42 estações devidamente georreferenciadas. Realizaram-se medições in situ de correntes e marés através de correntômetro e marégrafo-RBRduo, fixados na estação do porto de Macuse. O trabalho de campo compreendeu dois períodos: de 17 a 19 de novembro de 2013 e 16 a 21 de novembro de 2014. Os sedimentos em suspensão foram coletados com garrafa de Niskin específica para a coleta de sedimentos na lâmina de água. Os sedimentos foram filtrados utilizando um papel de fibra de $47 \mu \mathrm{m}$ de porosidade e uma bomba de vácuo, e quantificados numa balança eletrônica. Conduziu-se uma simulação hidrodinâmica através de um modelo numérico tridimensional ELCOM-CAEDYM que cobriu o período de amostragem no campo. A calibração e validação dos resultados simulados, foram realizadas por meio de uma comparação com os dados coletados em campo. Os resultados in situ e modelados indicaram marés de 4,0 m que geraram correntes entre $-0,8 \mathrm{~m} / \mathrm{s}$ e $+1,2 \mathrm{~m} / \mathrm{s}$. Seu regime hidrodinâmico cíclico, definiu a mecânica do transporte de sedimentos em suspensão do grupo de silte e areia fina por arrasto. A concentração de silte e areia fina obtida através da implementação do modelo ELCOM-CAEDYM, indicou concentrações de frações entre $\sim 100 \mathrm{mg} / 1$ e $300 \mathrm{mg} / 1$ nos períodos de marés 
enchentes e vazantes. Essas concentrações, sugerem a ocorrência de sedimentação no leito do rio por silte com fluxo inferior à $0,1 \mathrm{~cm} / \mathrm{s}$ e areia fina com fluxo inferior a $10 \mathrm{~cm} / \mathrm{s}$. Essas velocidades refletem o assoreamento do leito por frações muito finas de sedimento, causando modificações significativas na configuração geomorfológica do leito do estuário do Rio Macuse e nas possíveis operações portuárias.

\begin{abstract}
:
This manuscript study's the mechanics of suspended sediment transport in Macuse Estuary River in Mozambique, East Africa. The methodological approach was based on geomorphologic and oceanographic surveys covering 42 georeferenced stations. We conducted in situ tide and current measurements with a RBRduo tidal gauge and current-meter moored at the Macuse Harbour. The fieldwork comprised data collection in two periods, from 17th to 19th November 2013 and from 16th to 21st November 2014. Water samples were collected in a Niskin bottle for suspended sediment analysis. The sediments were filtered using a $47 \mu \mathrm{m}$ fiberglass and a vacuum pump, which were weighted in a highly precise electronic scale. Hydrodynamic simulations were conducted using a three-dimensional numerical model with the ELCOM-CAEDYM covering the period of in situ data collection. The calibration and validation of simulated results were performed through comparisons of field data and the simulated results. The in situ and modeled results indicated tides of $4.0 \mathrm{~m}$ in height that generated tidal currents between $-0.8 \mathrm{~m} / \mathrm{s}$ and 1.2 $\mathrm{m} / \mathrm{s}$. Its cyclic hydrodynamic regime defined the mechanics of sediment transport in suspension of the silt and fine sand group by dragging process. The concentrations of silt and very fine sand obtained through the implementation of the ELCOM-CAEDYM model indicated fractions between $\sim 100 \mathrm{mg} / \mathrm{l}$ and $\sim 300 \mathrm{mg} / \mathrm{l}$ during the ebb and flood tides. These concentrations suggest sedimentation in the riverbed by silt with a flow of less than $0,1 \mathrm{~cm} / \mathrm{s}$ and of very fine sand with a flow of less than $10 \mathrm{~cm} / \mathrm{s}$. The sedimentation in the bed can occur by very fine sand fractions that may cause significant modifications in the geomorphological configuration of the Macuse Estuary River and technical port operations.
\end{abstract}

\section{Introdução}

Os processos estuarinos são complexos e uma análise simples reprova ao tentar explicar processos de forma isolada. A combinação de vários fatores (regime de marés, ondas, fonte de sedimentos, carga do fundo, correntes de marés, descargas fluviais, processos de erosão e deposição nos leitos dos estuários e perfil geomorfológico do leito) para explicar os processos que ocorrem em estuários, pode-se mostrar efetiva (COOPER, 2001). Desse conjunto de fatores, foram selecionados e explorados para a análise no presente trabalho, o efeito da hidrodinâmica estuarina que inclui o regime de marés, as correntes de marés e descargas fluviais, combinados com o perfil geomorfológico do leito, e a dinâmica de sedimentos suspensos. Obviamente, os sedimentos suspensos e finos são a principal componente de um sistema fluvial (KNIGHTON, 1998), provenientes da erosão das bacias de drenagem e do leito do próprio estuário. Várias pesquisas têm indicado que os sedimentos finos são as principais fontes de contaminação de estuários, o que causa um aumento de entrada de nutrientes (EDWARDS et al.,
2000) e contaminantes nos rios (STONE \& HAIGHT, 2000). Na perspectiva geomorfológica, os sedimentos suspensos são o principal fator causador da mudança dos perfis geomorfológicos através dos processos de deposição e erosão.

Os estuários de Moçambique são as principais vias de transferência de água doce, sedimento, nutrientes e poluentes da região continental para o Oceano Índico. Grande parte do material sedimentar estuarino desses ambientes é proveniente da erosão da bacia de drenagem, cujos principais constituintes são silte e argila, que compõem partículas inferiores, que também foram identificadas por SCHETTINI (2003) em ambientes similares no Brasil. Geralmente, os sedimentos suspensos na lâmina de água em estuários, afetam o ambiente físico e químico pela ressuspensão e transporte hidrodinâmico (BOWERS et al., 2004). Por outro lado, atenuam a penetração da luz e o ciclo de nutrientes e poluentes orgânicos. O conhecimento da dinâmica de sedimentos suspensos é essencial para quantificar o fluxo de substâncias úteis quimicamente e ecologicamente, inclusive a evolução geomorfológica dos leitos de estuários. 
Estudos extensivos de transporte de sedimentos em suspensão em estuários dominados pelo regime de marés são relativamente comuns e bem documentados em diversas partes do mundo, entre estes: BIGGS (1970) na Baia de Chesapeake nos Estados Unidos; GELFENBAUM (1983) e FAIN et al. (2001) no estuário do Rio Colômbia; PATCHINEELAM e KJERFVE (2004) no estuário de Winyah nos Estados Unidos; KAPPENBERG et al.(1996) no estuário de Elbe; LIMA et al. (2001) na baia de Santos no Brasil e, GRABEMANN \& KRAUSE (2001) no estuário de Waser na Alemanha. Especificamente na costa oriental do continente africano, estudos sobre esse tema em ambientes de transição entre o oceano e o continente são relativamente poucos (KITHEKA et al., 2005; COOPER, 2001). Apesar da observância persistente da ausência de pesquisas de sedimentos suspensos na costa sudeste africana, KITHEKA et al. (2005) estudou as descargas fluviais, transporte de sedimentos e sua troca no estuário de Tana na Tanzânia e teve resultados plausíveis. Uma análise geomorfológica de referência africana foi realizada por COOPER (2001), que estudou o papel das inundações extremas na dinâmica estuarina e costeira, seus contrates entre rios e estuários dominados por micro marés em toda a costa da República da África do Sul. Na costa de Moçambique, NEHAMA (2012) estudou a dispersão da pluma de água doce, no famoso Banco de Sofala( entre o rio Save e Província de Nampula-Figura 1), e teve resultados emblemáticos na perspectiva oceanográfica. Recentemente, CHEVANE et al. (2016) estudaram o efeito das marés na estratificação vertical da lâmina de água no Banco de Sofala e obtiveram resultados plausíveis conforme os objetivos propostos. Nenhum desses estudos focou nos ambientes de transição entre o oceano e o continente, apesar de existir na costa moçambicana centenas de estuários com caraterísticas geomorfológicas diferentes. De fato, esses ambientes de transição são palco da ocorrência de vários processos geológicos, geomorfológicos e oceanográficos que carecem de explicações científicas coerentes e consistentes. Acredita-se que o surgimento desses ambientes transicionais procedeu após as variações relativas do mar ocorridas desde o fim do Pleistoceno que estendeu-se até ao Holoceno (ARMITAGE et al. 2006; RAMSAY, 1995).

Estudos de material particulado em suspensão com grau de detalhe relativamente alto no estuário do rio
Macuse ainda são escassos, incluindo os outros estuários da costa de Moçambique que integram o trecho entre do Rio Rovuma e Ponta do Ouro. A compreensão dos aspectos geológicos, geomorfológicos, e oceanográficos do referido estuário é importante para o entendimento da dinâmica sedimentar da área em estudo. A hidrodinâmica do estuário do Rio Macuse, apesar das suas diferenças de localização geográfica, da dinâmica sedimentar e da sua geomorfologia, é semelhante a outros estuários do mundo. Segundo ROSA (2010) acredita-se que essas semelhanças são causadas de forma similar pela hidrodinâmica estuarina, das assimetrias de marés, as correntes de marés, aos processos de sedimentação decorrente de condições geológicos-geomorfológicas, ao regime de ventos, ao clima de ondas, as precipitações pluviométricas e as descargas fluviais. A atuação desses fatores ambientais difere em magnitude e podem criar zonas de erosão ou deposição ao longo do canal de navegação.

O estuário em estudo, já foi referência regional no transporte de vários produtos e mercadorias para a região centro de Moçambique e para os países vizinhos (Malâwi, Zimbabwe e Zâmbia) através do porto de Macuse. Recentes projetos conduziram ao governo de Moçambique a decisão definitiva de construção de um porto de águas pouco profundas neste estuário. Segundo JENSEN et al. (1999), o projeto de construção de um porto no estuário, exemplo do Rio Macuse, requer estudos prévios de transporte de sedimentos e geomorfológicos, que podem auxiliar na identificação de graves problemas de assoreamento periódicos ou contínuos. Nesta perspectiva, objetiva-se através do presente estudo descrever a mecânica do transporte de sedimentos em suspensão em curto prazo a partir de dados coletados no estuário de Macuse combinados com resultados obtidos da aplicação de um modelo numérico ELCOM-CAEDYM, específico para as zonas de transição entre o continente e o oceano.

\section{Descrição da área de estudo}

O estuário de Macuse localiza-se na Província da Zambezia, no centro de Moçambique, na região leste da África Austral (Figura1). Insere-se administrativamente no Distrito de Namacurra, entre as coordenadas geográficas, $17^{\circ} 48^{\prime} 1,43^{\prime}$ ' $\mathrm{S}$ de latitude e $37^{\circ} 04^{\prime} 00 \mathrm{E}$ de longitude. Limita-se a leste pelo Oceano Índico, a norte 
e oeste pelo Posto Distrital de Namacurra Sede e a Sul pelo Distrito de Nicoadala. Esse estuário constitui um dos meios de navegação fluvial da zona centro de Moçambique, e é importante no desenvolvimento de várias atividades económicas portuárias com grande impacto na Província da Zambézia e alguns países do interior da África Austral (Zimbabwe, Zâmbia e Malâwi).

O rio apresenta um comprimento de cerca de 30 $\mathrm{km}$ da nascente até a desembocadura com o oceano Índico. É caracterizado por uma rede de pequenos afluentes que desaguam no canal principal. O clima de ondas é caraterizado por ondas de cerca de 1,0 m de altura e um regime de marés semi-diurnas, com alturas que variam entre -0,5 e 4,0 metros (INAHINA, 2015). A escala de Köppen auxiliou melhor na identificação do clima da região e, integra-se perfeitamente entre a faixa tropical húmido e subequatorial. Existem duas estações anuais bem definidas, a) -o verão que inicia do mês de setembro e termina em março. Essa estação é caraterizada por temperaturas do ar que atingem máximo de $40{ }^{\circ} \mathrm{C}$ e uma temperatura média estimada de $32^{\circ} \mathrm{C}$. b) o inverno que estende-se deste o mês de abril até agosto, caraterizado por temperaturas relativamente baixas ao verão com máxima de $28^{\circ} \mathrm{C}$ e mínima de $16^{\circ}$ C. O regime de ventos é predominantemente de Sudeste e Leste, com ventos de intensidade fraca a moderados nas duas estações do ano. Segundo o Ministério Da Planificação E Desenvolvimento de Moçambique (2013), o índice de precipitação pluviométrica é superior a 1300 $\mathrm{m} / \mathrm{ano}$, provocando inundações durante os meses de dezembro a abril. Essa precipitação pluvial aumenta de forma significativa o escoamento das águas das bacias de drenagem da região, inclusive do Rio Namacurra. Consequentemente, o estuário de Macuse torna-se um laboratório natural onde ocorrem diferentes processos geológicos, geomorfológicos e oceanográficos.

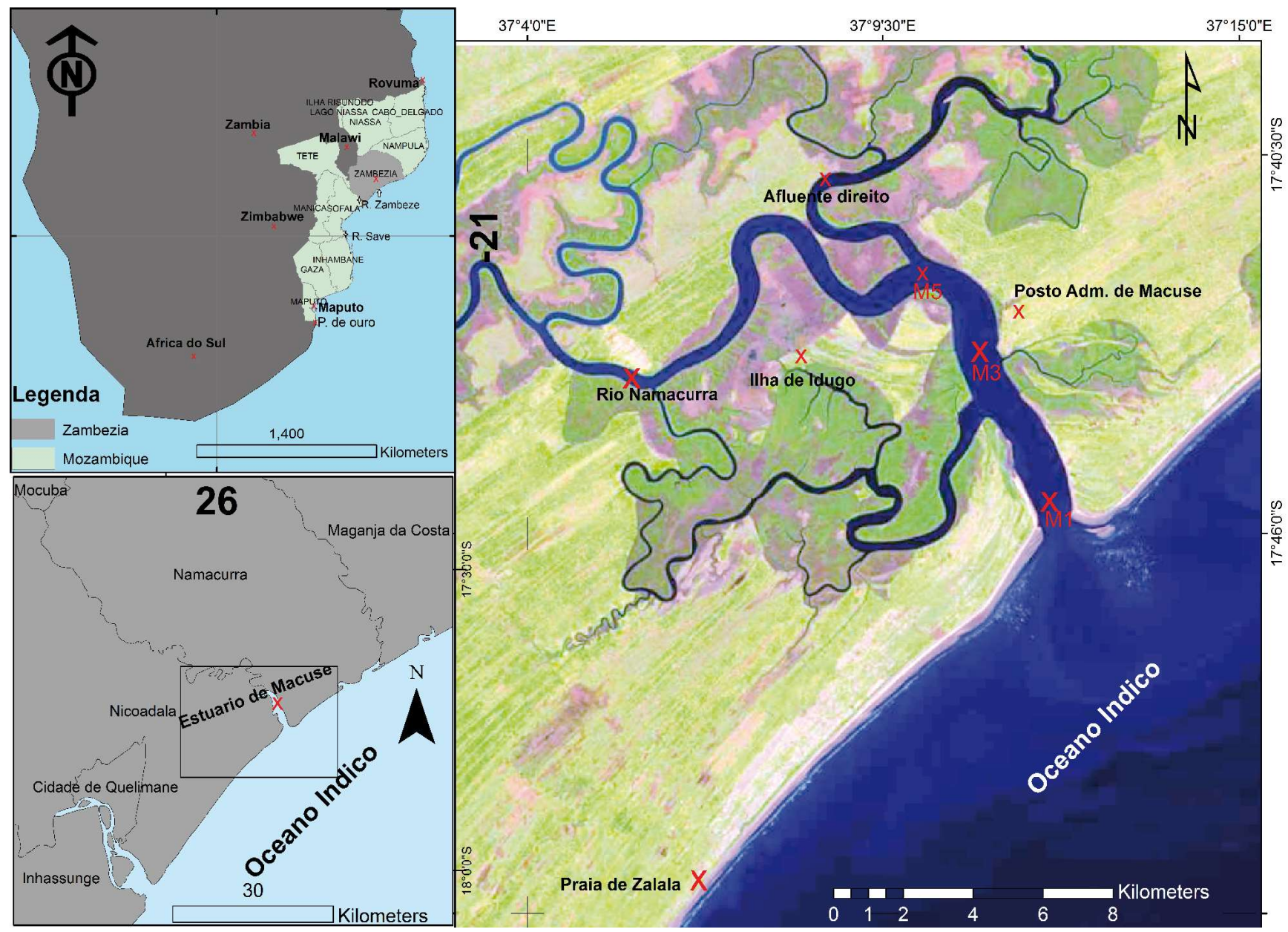

Figura 1 - Localização da área de estudo no contexto do litoral de Moçambique, sudeste Africano. As estações de observação estão indicadas por texto ao longo do rio. 


\section{Enquadramento geomorfológico regional da área de estudo}

A costa de Moçambique é dividida em três regiões: a) a região norte que compreende o trecho litorânea entre a desembocadura do Rio Rovuma e o delta do Zambeze. Nesse seguimento litorâneo, MOREIRA (2005) fez uma radiografia geral e observou que ele é caracterizado por uma faixa estreita, tectógena, na margem dos planaltos da província de Cabo Delgado e Nampula. Esta mesma análise, mostrou que essa região é dominada por arribas e praias anexas, com uma franja recifal e ilhas coralígenas na plataforma continental adjacente, também estreita; b) a região central, que integra o trecho litorâneo que começa do delta do Rio Zambeze (que divide a fronteira entre as províncias da Zambézia e Sofala) e o Rio Save (que divide a região centro do sul). Geralmente, essa região apresenta uma configuração geomorfológica específica de larga planície fluvial e marinha, relativamente baixa, arenosa e lodosa (RAMSAY,1995; MOREIRA, 2005). Nos tais sistemas, observa-se um laboratório natural de ocorrência persistente de processos dominados pela hidrodinâmica de correntes de maré e assimetria de marés. A hidrodinâmica dessa região é considerada em alguns trechos da costa moçambicana como causadora da erosão, que é um processo da dinâmica litoral que ocorre em toda a costa moçambicana, com taxas relativamente diferentes; e c) a região sul que situa-se entre o Rio Save e a ponta do Ouro, na fronteira sul com a República da África do Sul. A combinação de variações relativas do mar ocorridas desde o fim do Pleistoceno que estenderam-se ao Holoceno (RAMSAY,1995), gerou a formação de uma extensa planície arenosa, com praias anexas a arribas eolianíticas, ou a sistemas de dunas de até $120 \mathrm{~m}$ (dunas de Bilene), lagunas (sistema laguna-barreira de Bilene e Quissico), ilhas-barreira (Inhaca, Bazaruto) e plataformas-barreira de rochas de praia (exemplo de Xai-Xai em Gaza) que ocorrem no espraiado e na plataforma continental. Os processos eólicos evidentes sobre esses sistemas geram campos de dunas eólicos que estendem-se até Durban na República da África do sul.

Informações regionais do processo de deposição da área de sugerem que os sedimentos depositados nesse ambiente de transição devem-se as variações do nível relativo do mar que ocorreram deste o início do Holoceno estudo (BOTHA \& PORAT, 2000; BOTHA et al.,2003). Picos específicos de transgressão máxima ocorreram entre 7000 e 5000 anos A.P., enquanto picos de regressão ocorreram desde 2000 yrs.B.P. (RAMSAY, 1995) que estendem-se até o presente. A combinação das transgressões e regressões e o fornecimento de sedimentos, formou várias planícies de marés caraterizadas por praias com areia muito fina e fina e vários campos de manguezais que estendem-se até cerca de $40 \mathrm{~km}$ para interior do continente. Esses campos são compostos por várias espécies de vegetação típica de mangue com abundância de material muito fino (lama, argila e silte) e colonizados por populações de bentos e moluscos.

\section{Materiais e métodos}

\section{Coleta de dados}

Foi definida uma série de estações oceanográficas de coleta de dados e amostras de sedimentos suspensos (Figura 2). As estações foram determinadas de modo a garantir maior cobertura na área de estudo, com o propósito de determinar de forma extensiva os perfis longitudinais e transversais de temperatura, correntes de marés, elevação de superfície, velocidade do vento, salinidade e turbidez da água no mês de novembro dos anos de 2013 e 2014. Realizou-se a medição dos parâmetros físicos e geoquímicos utilizando a sonda multi-parâmetro RBRCTD (contendo sensores de salinidade, temperatura, turbidez, oxigénio dissolvido, $\mathrm{pH}$, pressão e chorofila-a), acoplado num barco a motor. O RBRCTD foi configurado para coletar automaticamente uma série de dados numa frequência de $6 \mathrm{~Hz}$, descendo desde a superfície até ao fundo a uma taxa média de $0,5 \mathrm{~m} / \mathrm{s}$.

Os dados meteorológicos (precipitação, velocidade do vento) foram adquiridos no Instituto Nacional de Meteorologia de Moçambique (INAM) que coleta estes dados de forma rotineira numa rede de estações suficientemente densa. Os dados hidrológicos (vazões do rio) foram adquiridos na Direção Nacional de Águas de Moçambique entre 2000 e 2013 na estação 91 do Rio Licungo em Mocuba, que registra e fornece valores da altura de água atingida em 24 horas. Usando o fator de conversão fornecido dela DNA, as alturas foram transformadas em volumes descarregado pelo rio. Os dados foram ajustados segundo a relação $\mathrm{A}_{\mathrm{n}}=\varepsilon 526,32$ $\mathrm{B}_{\mathrm{n}}\left[\mathrm{m}^{3} \mathrm{~s}^{-1}\right]$, onde $\mathrm{A}_{\mathrm{n}}$ é a vazão a ser determinada, $\mathrm{B}_{\mathrm{n}}$ é o valor da média mensal observada, e $\varepsilon$ corresponde a constante de otimização. 
Para determinar a quantidade de sedimentos suspensos ao longo das estações, conduziu-se um processo de coleta de 1,0 litro de amostra de água utilizando uma garrafa de Niskin (3,5 L) em três profundidades (superfície, meio e no fundo) da coluna de água, e posterior análise laboratorial. A quantificação dos sedimentos contidos numa amostra de água seguiu a metodologia proposta por RAO et al. (2011), que consistiu na filtragem da amostra de água, secagem do filtrado, e deter- minação do peso do filtrado seco e húmido. A filtragem envolveu a passagem da amostra através de filtros de fibra de vidro pré-aquecidos a $60{ }^{\circ} \mathrm{C}$, com $0,47 \mu \mathrm{m}$ de porosidade e $0,45 \mathrm{~mm}$ de diâmetro utilizando um cilindro transparente acoplado a uma bomba de vácuo. A secagem decorreu a $150^{\circ} \mathrm{C}$ em forno elétrico durante um tempo médio de cerca de 10 minutos. O cálculo total de sedimentos suspensos foi realizado pela diferença do peso inicial e final.

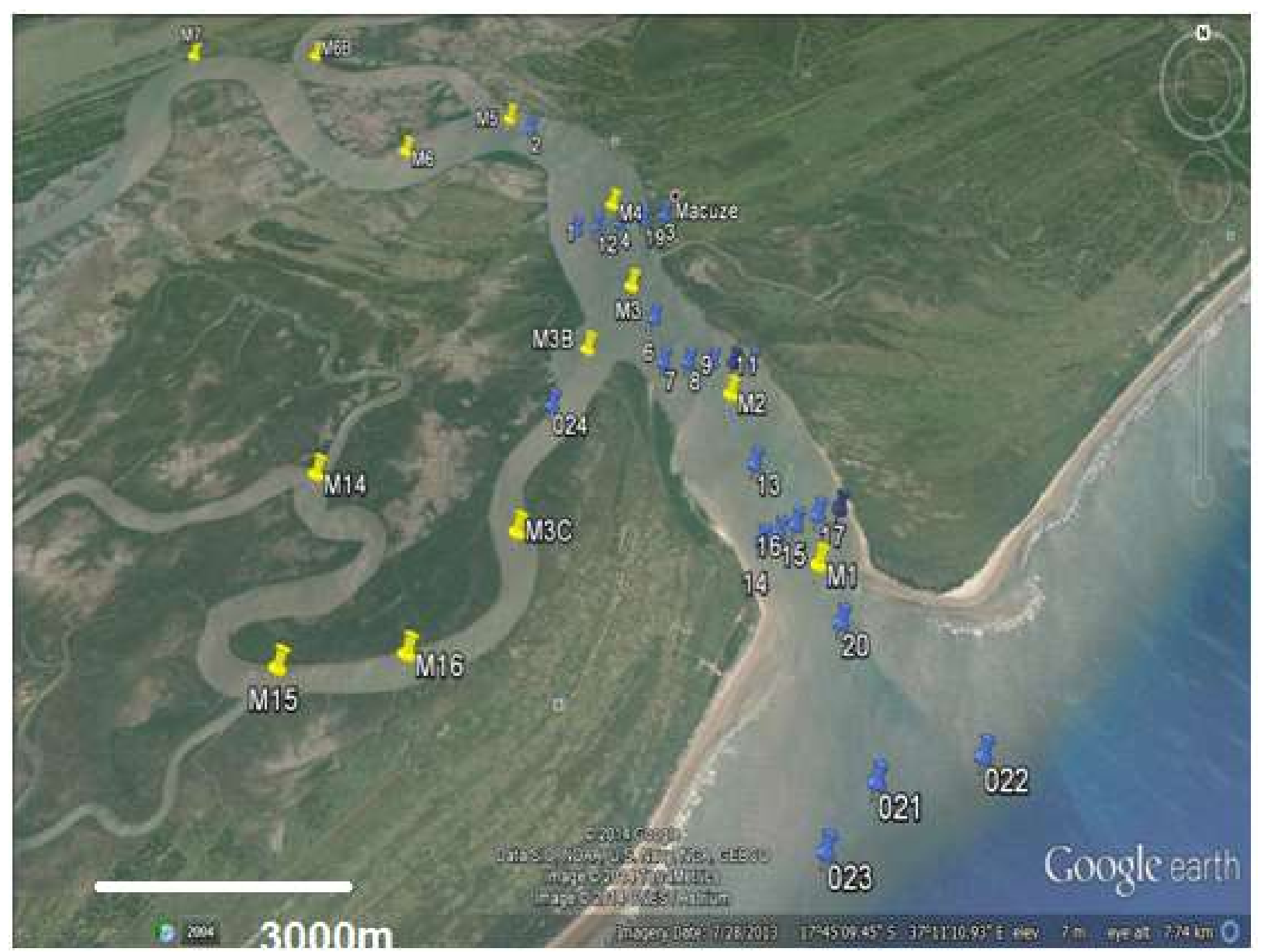

Figura 2 - Estações de coleta de dados em Novembro de 2013 (amareladas) e 2014 (azuladas).

\section{O modelo numérico ELCOM-CAEDYM}

O modelo utiliza os princípios termodinâmicos e hidrodinâmicos, para simular o comportamento espacial e temporal de parâmetros físico (temperatura, poluentes, salinidade e correntes de água), biológicos (fito-plâncton, zooplankton, peixe, Miscellaneous $e$ biomassa bacteriana), geoquímicos (nutrientes, sólidos suspensos, refractory carbon, componentes biológicos ativos, componentes químicos e minerais geológicos) e geomorfológicos (a topografia, erosão, deposição, declividade, etc.). Este modelo foi selecionado por ter sido já testado em outros estudos, como MIGUEL (2013), HODGES (2013), HODGES (2007) e tiveram resultados plausíveis. O modelo ELCOM-CAEDYM incorpora várias componentes consoante o fluxograma apresentado na Figura 3, onde o código numérico da componente principal (o módulo ELCOM) está redigido na linguagem Fortran 90. O esquema resume as variá- 
veis chaves para a execução do módulo, que envolve: pré-processamento de dados que consiste na preparação da batimetria, a definição das condições de fronteiras e iniciais, preparação de dados meteorológicos e descar- gas fluviais. Por outro lado, é pertinente a configuração das variáveis dos sedimentos suspensos no módulo CAEDYM em condições iniciais e preparação das variáveis geoquímicas e biológicas a serem simuladas.

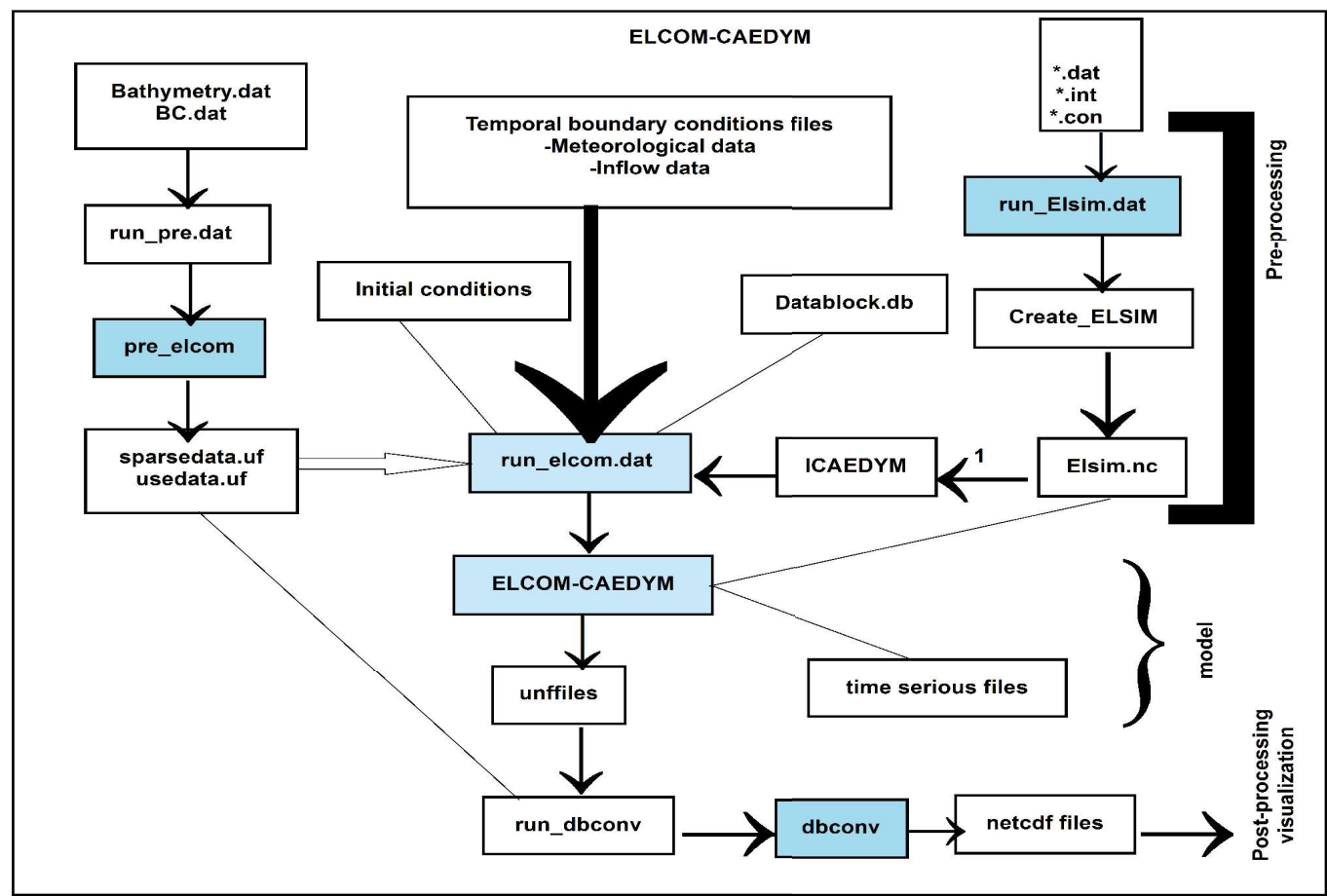

Figura 3 - Fluxograma do funcionamento dos módulos do ELCOM-CAEDYM (adaptado de Hodges, 2003).

A componente CAEDYM incorporou para além de propriedades físicas, as componentes químico-biológicas e geomorfológicas. Foram ainda introduzidos dados meteorológicos de descargas pluviais e fluviais que são de forçantes do modelo, indispensáveis na simulação de sólidos dissolvidos e material particulado em suspensão. Os dados definidos no ELCOM-CAEDYM foram processados simultaneamente para a produção de ficheiros NetCDF em três tipos, nomeadamente: perfis verticais, horizontais em cortina e em malha. A fase do pós-processamento corresponde aos resultados em formato NetCDF que foram convertidos e lidos para sua visualização através de comandos estruturados em Fortran e no Matlab.

\section{Configuração do ELCOM-CAEDYM para o Estu- ário de Macuse}

O pré-processamento incluiu a preparação da batimetria com as respetivas condições de fronteira. Foi definida uma malha batimétrica na escala de 1:10000 do Rio Macuse, representando uma grelha numérica com dimensão 20 m x $20 \mathrm{~m}$ e um total de 230 x 190 pontos na direção X, e Y respectivamente. As cotas batimétricas utilizadas nesta malha foram baseadas nos levantamentos efetuados pelo Instituto Nacional de Hidrografia e Navegação de Moçambique (INAHINA) em 1986, que posteriormente foram atualizados com dados batimétricos obtidos no âmbito deste estudo através duma eco-sonda Garmin-150. A batimetria numérica foi produzida no programa Mike 21 desenvolvido pela DHI na Dinamarca, após uma digitalização dum mapa que cobre a área da Figura 4, incorporando as cotas atualizadas por meio de uma interpolação bilinear.

A malha computacional incluiu três fronteiras abertas, sendo duas correspondentes aos rios (Namacurra e afluente direito) nas quais foram introduzidas dados de vazão calculada a partir da altura hidrométrica da estação 91 da DNA (na razão 2/3 e 1/3). A terceira fronteira aberta corresponde a interface com o oceano, onde foi introduzida a onda de maré do modelo Model_tpxo7 com a resolução global de $1 / 4^{\circ} \times 1 / 4^{\circ}$ disponível em http://www.coas.oregonstate.edu/research/po/research/ tide/index.html). A extração da elevação da onda de maré do modelo global Model_tpxo7 foi realizada na 
desembocadura do estuário no ponto $37,22^{\circ} \mathrm{E}$ e $17,76^{\circ} \mathrm{S}$. $\mathrm{Em}$ todas fronteiras foram definidos valores constantes de salinidade e temperatura, e inicialmente, todo volume de água no domínio computacional foi tomado como quiescente e verticalmente bem misturado. Foi definido um intervalo de tempo para a simulação de 120 segundos, e realizadas um total de 210000 iterações, tendo sido gravados resultados a cada hora de simulação.

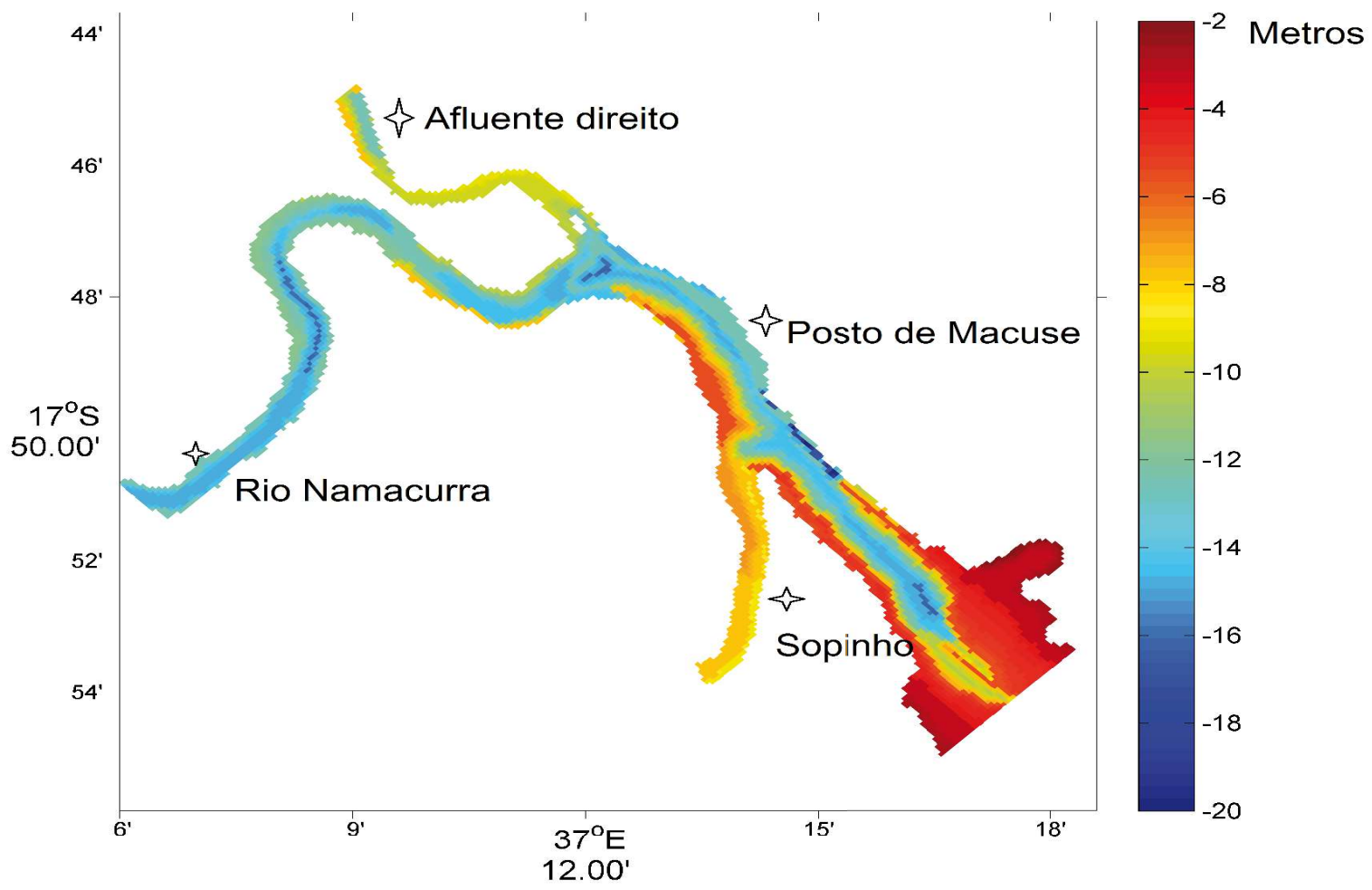

Figura 4 - Mapa batimétrico digitalizado na escala 1:10000 do estuário do Rio Macuse, Moçambique.

Foi conduzida uma verificação técnica do modelo e monitoramento mensal da sua estabilidade hidrodinâmica. $\mathrm{O}$ desempenho do modelo mostrou-se efetivo alcançando uma estabilidade dentro dos padrões recomendados através do cálculo da constante de estabilidade CFL. O tempo de estabilidade foi calculado através da fórmula: $\sqrt{g^{\prime} D} \frac{\Delta t}{\Delta x}<\sqrt{2}$, onde $\mathrm{g}^{\prime}$ foi considerado 100 (parâmetro máximo estimado para águas rasas), $\mathrm{D}=8.0$ $\mathrm{m}$ (profundidade média do estuário), $\Delta t$ o tempo a ser estimado, $\Delta x=20 \mathrm{~m}$ (corresponde ao tamanho da grelha da batimetria). A estabilidade foi determinada teoricamente pelos princípios do ELCOM-CAEDYM por $C F L=\frac{\Delta t L}{4}$. Essa verificação também foi realizada através da comparação com os dados de salinidade coletados no campo e modelados, inclusive uma comparação de marés que incluiu as mesmas constituintes lunares e solares (M2, S2, N2, K2, k1, O1, P1, Q1, Mf, Mm e M4).

\section{Resultados e discussão}

A calibração com os dados coletados de campo foi realizada através da comparação das marés do modelo e as do campo (Figura 5), e posterior seleção dos valores iniciais de estratificação através da salinidade e da elevação da maré, usando a aproximação de tentativa-erro. A tentativa de erro da maré observada e modelada foi calculada em $0,3 \mathrm{~m}$ enquanto a salinidade foi de 0,7 respectivamente. Esses valores indicam um erro relativamente no contexto e escala de análise desejada neste trabalho, o que conduz a uma conclusão de uma aproximação credível e robusta na perspectiva numérica.

Diferentes análises foram conduzidas sobre os resultados produzidos pelo modelo selecionado e dados coletados em campo. Por exemplo, na Figura 6, são apresentados resultados espaciais de velocidades de correntes no período da vazante e enchente geradas pelas marés. Essas correntes apresentaram diferentes intensidades, que são fator determinante na dispersão dos sedimentos suspensos e transporte das partículas por arrasto. Sua geração foi devido a introdução das marés na fronteira M1, que posteriormente foram originadas correntes de marés na vazante de até $1,20 \mathrm{~m} / \mathrm{s}$ da compenetre $\mathrm{U}$, e cerca de 0,6 $\mathrm{m} / \mathrm{s}$ da componente $\mathrm{V}$. Enquanto as correntes de enchente variaram entre $-0,2 \mathrm{~m} / \mathrm{s}$ e $0,4 \mathrm{~m} / \mathrm{s}$ de $U$ e entre $-0,2 \mathrm{~m} / \mathrm{s}$ e 
$0,2 \mathrm{~m} / \mathrm{s}$ de $\mathrm{V}$. A análise do módulo das duas componentes de correntes nos dois períodos indicou velocidades médias de $1,2 \mathrm{~m} / \mathrm{s}$. SHI (2010) observou em estudo semelhante correntes de marés de $1,2 \mathrm{~m} / \mathrm{s}$ na maré de sizígia nas camadas do fundo de estuário Changjiang na China. Tal resultado, apesar das diferenças apresentadas entre os dois sistemas estuarinos, concorda com a velocidade máxima encontrada no pico de marés de sizígia de 1,2 $\mathrm{m} / \mathrm{s}$ na vazante. Sua intensidade variou periodicamente

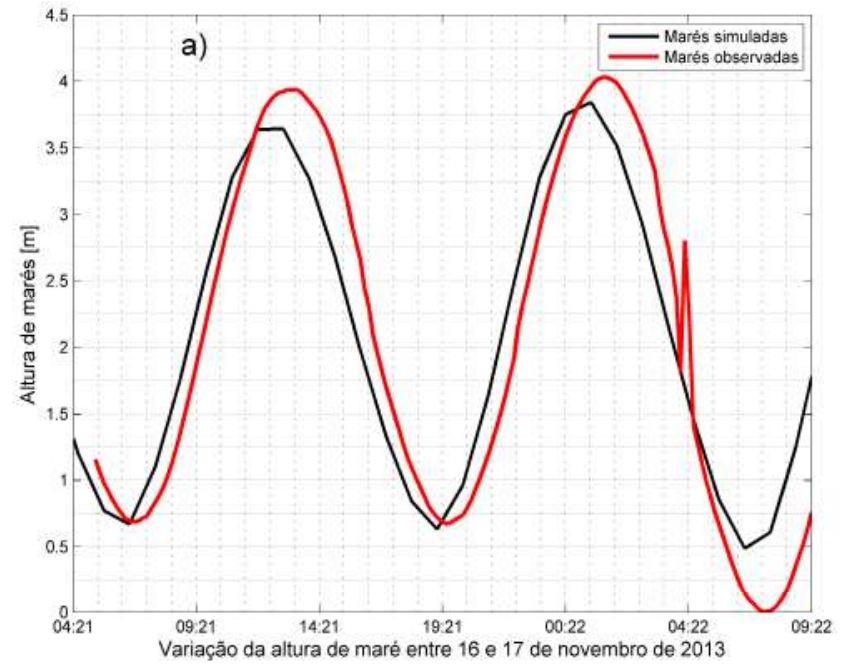

conforme o regime de marés, em que o período de maré vazante registrou-se velocidades relativamente baixas que na enchente. SHI (2010) calculou a velocidade de deposição vertical de lama/silte entre $0,04 \mathrm{~cm} / \mathrm{s}$ e 0,41 $\mathrm{cm} / \mathrm{s}$, que é o mesmo encontrado no presente trabalho de $0,1 \mathrm{~cm} / \mathrm{s}$ para o grupo de silte e $10 \mathrm{~cm} / \mathrm{s}$ para areia fina. As diferenças devem-se as caraterísticas geomorfológicas dos dois sistemas, do tipo de sedimento e a magnitude da hidrodinâmica do sistema estudado.

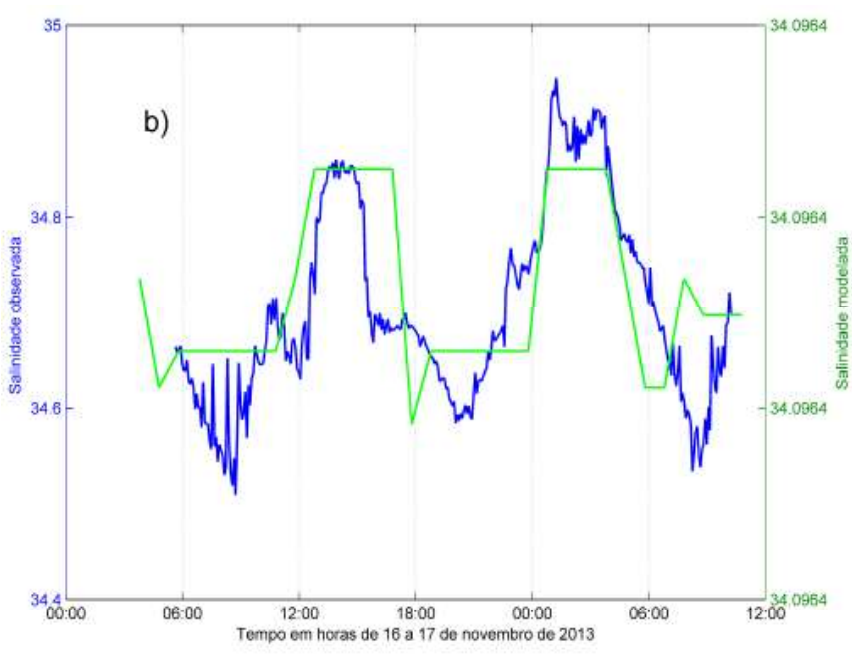

Figura 5 - Variação da altura da maré (a) e salinidade observada e modelada (b) na estação M3 durante cerca de $24 h$.
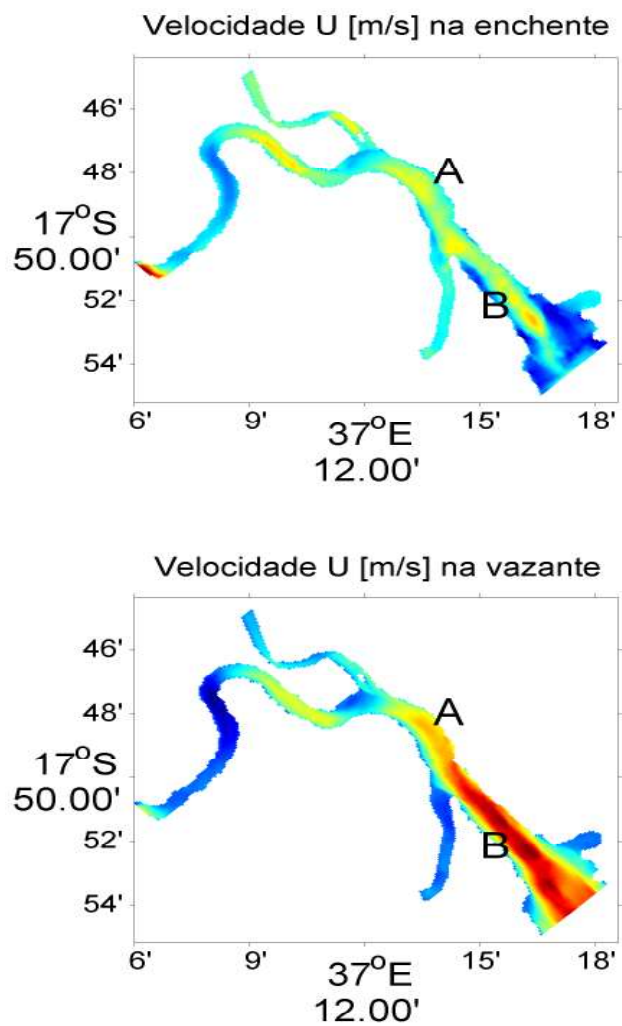
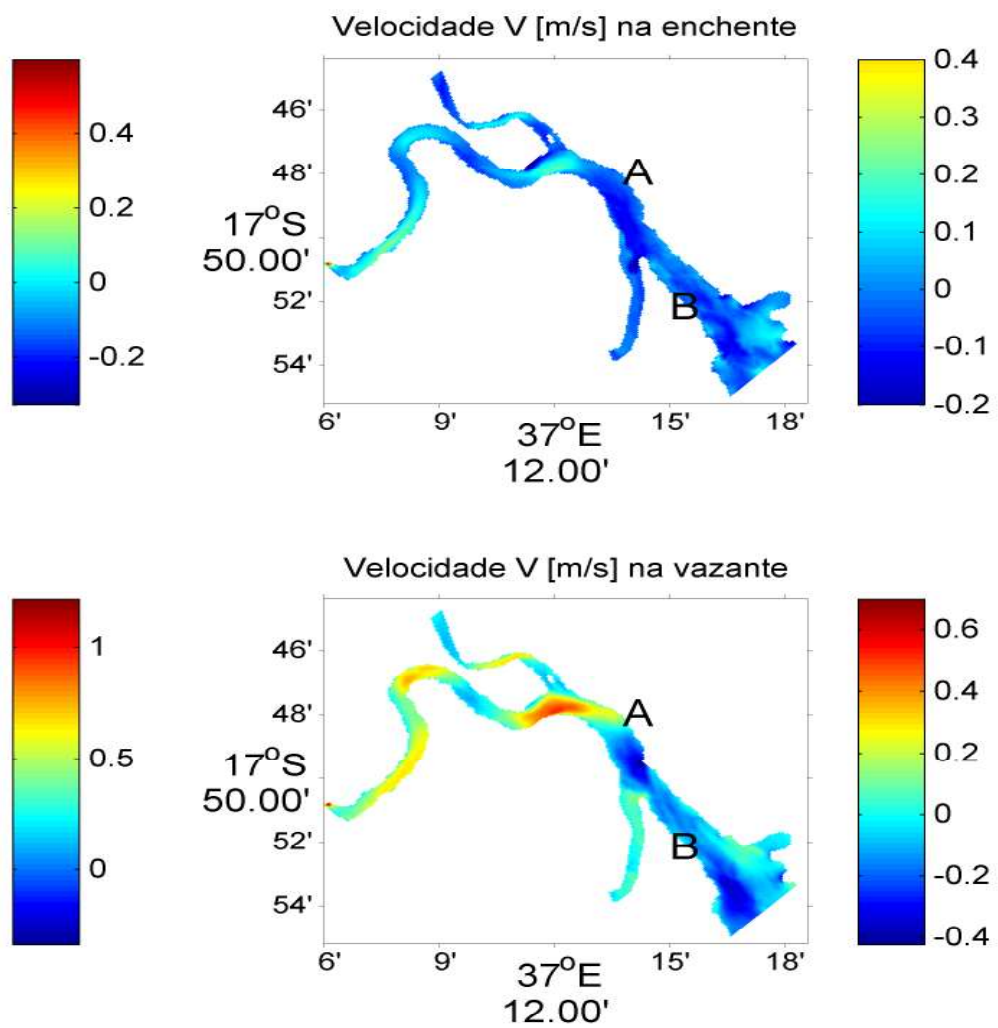

Figura 6 - Variação de correntes de marés nos periodos de vazante e enchente dos dias 16 e 17 de novembro de 2014. A e B são os locais propostos para a implementação do projeto da construção do porto de Macuse. 
A batimetria do estuário, mostrou profundidade máxima de $20 \mathrm{~m}$ no porto de Macuse, com uma declividade relativamente suave. Segundo SIMONS E RICHARDSON (1966), geralmente essa mudança da tal declividade em estuários dominados por marés e descargas de águas de rios, pode alterar a configuração do leito do canal quando a profundidade da água permanece constante. De fato, a profundidade do estuário de Macuse foi considerada constante para cada cota ao longo da simulação, uma vez que o coeficiente de dragagem do fundo foi considerado constante. Observou-se persistentemente que a variação das correntes de marés foi dependente de vários fatores combinados que inclui, a declividade do leito, carga suspensa, o regime de marés, o perfil morfológico e a geologia da área. O efeito da declividade combinado com o perfil morfológico foi discutido por MORGAN (1980) e por HADLEY et al. (1985). Esses autores chegaram a conclusão plausível que mostrou uma relação direta de acréscimo na declividade com o aumento na velocidade do escoamento superficial e sua capacidade de erosão. Tal discussão é válida no sistema estudado, pois observou-se diferentes velocidades ao longo do canal que variaram de forma concordante com o perfil morfológico do leito e velocidades relativamente baixas na enchente e fortes na vazante (Figura 6)

O perfil morfológico do leito de Macuse é determinante, pois segundo BIAZIN et al (2008), o trans- porte dos sedimentos está intimamente relacionado à migração da configuração do leito e ambos resultam do movimento alternado das partículas isoladas. Esta afirmativa, é verdadeira quando relaciona-se os dois grupos de sedimentos simulados (posteriormente apresentados nas figuras 8,9 e 10) pelo modelo com a velocidade das correntes de marés (Figura 7) e geometria da batimetria digitalizado. Verifica-se na figura 7 que a velocidade $U$ foi maior na vazante com cerca de $0,8 \mathrm{~m} / \mathrm{s}$ enquanto que na enchente a velocidade foi relativamente menor com máxima de $0,2 \mathrm{~m} / \mathrm{s}$. A velocidade $\mathrm{V}$ foi menos intensa no canal com velocidade que variou entre - 0,2 e $0,2 \mathrm{~m} / \mathrm{s}$ na enchente, enquanto na vazante a velocidade variou entre $-0,2$ e $0,5 \mathrm{~m} / \mathrm{s}$. Essas velocidades caracterizaram o leito do canal com velocidades relativamente baixas de até $0 \mathrm{~m} / \mathrm{s}$, o que terá permitido a deposição de material suspenso ou arrastado pela ação da correnteza da água. As diferenças entre as correntes $\mathrm{U} \mathrm{e} \mathrm{V}$ indicam de forma evidente que a componente $\mathrm{U}$ foi o fator determinante para o transporte de material particulado em suspensão devido à disposição do leito e geometria $\mathrm{E}-\mathrm{W}$ do canal do Rio Macuse. Os resultados descritos da velocidade de correntes de marés no processo de deposição, corroboram com BIAZIN et al (2008), o seu padrão sugere que as partículas podem depositar-se em lugares diferentes no leito e com períodos de repouso diferentes e diferentes velocidades de transporte.
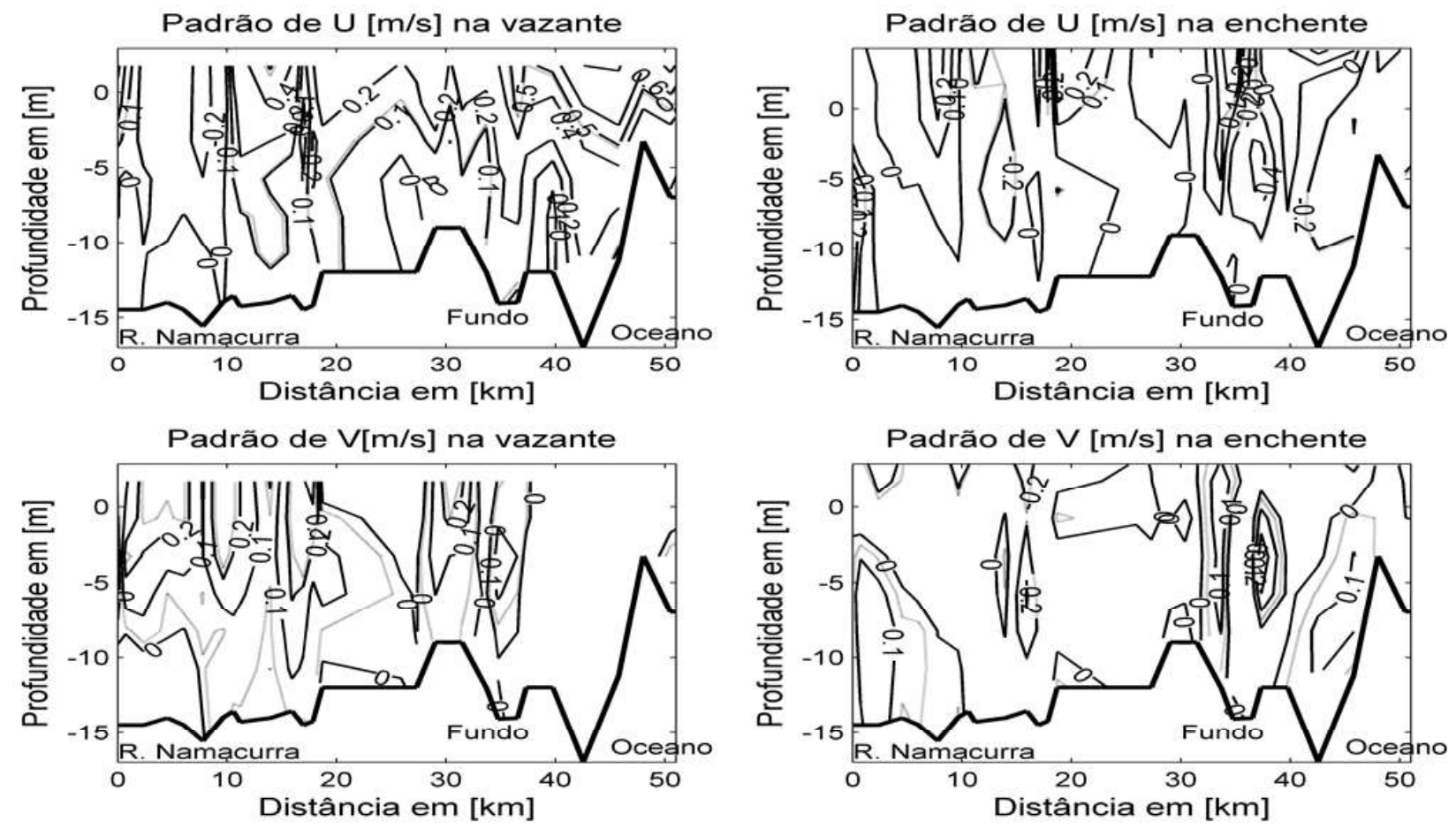

Figura 7 - Padrão de correntes de marés na vazante (esquerda) e enchente (direita) de componentes $U$ e $V$. 
A escolha da estação M5 da Figura 8, foi estratégico para a análise de sedimentos suspensos dos rios $\mathrm{Na}-$ macurra e afluente direito que drenam vários elementos essenciais que auxiliam a análise de parâmetros físico-químicos e morfológicos. Nessa estação, os resultados da salinidade indicaram valores de cerca de 34 que é relativamente menor que nas estações M3 e M1. Tal observação deve-se as descargas dos rios Namacurra combinados com a contribuição de seus tributários que drenam grandes quantidades de volumes de água doce durante o período chuvoso entre janeiro e março. Essas descargas dominam periodicamente o estuário na estação chuvosa, diluindo de forma significativa a concentração de salinidade na maré de quadratura ou sizígia criando um grau de mistura muito alto. Contrariamente na maré de sizígia da estação seca, o estuário é dominado pela água salgada proveniente do Oceano Índico, causando um incremento de densidade que varia entre $1023 \mathrm{~kg} / \mathrm{m}^{3}$ e $1026 \mathrm{~kg} / \mathrm{m}^{3}$. A salinidade observada no período em análise, não mostrou uma variação significativa com valores de cerca de 34,0, porém inferior que nas estações M3 e M1.

Verificou-se que a concentração de sedimentos em suspensão de silte e areia fina variou entre 100 e 300 $\mathrm{mg} / \mathrm{l}$, com uma forte dependência do regime de marés que gerou correntes de até $1,2 \mathrm{~m} / \mathrm{s}$. Essa velocidade combinada com a declividade do leito do estuário, das descargas do Rio Namacurra e o perfil geomorfológico definiu o transporte dos sedimentos suspensos do rio Namacurra para a desembocadura. Essa dependência indicou que o estuário é dominado por marés na estação seca e por descargas de água doce na estação chuvosa entre janeiro e maço. A concentração de sedimentos dos dois grupos na lâmina da água indicou no período analisado, um máximo de $300 \mathrm{mg} / 1$ para silte e $210 \mathrm{mg} / 1$ para areia fina. Essas concentrações indicaram maior concentração que as estações M3 e M1 uma vez que está localizada nas proximidades da fonte principal de sedimentos. $\mathrm{O}$ fator fonte de sedimentos provenientes de rios também foi observada por FIGUEIREDO \& CALLIARI (2006) em ambiente transicional semelhante, na Laguna dos Patos do Brasil. Assim, independente da escala ou volume dos sedimentos suspensos, as concentrações encontradas corroboram com FIGUEIREDO \& CALLIARI (2006), pois geraram alterações na mobilidade dos perfis do leito do estuário, causando modificações morfodinâmicas e sedimentológicas significativas.
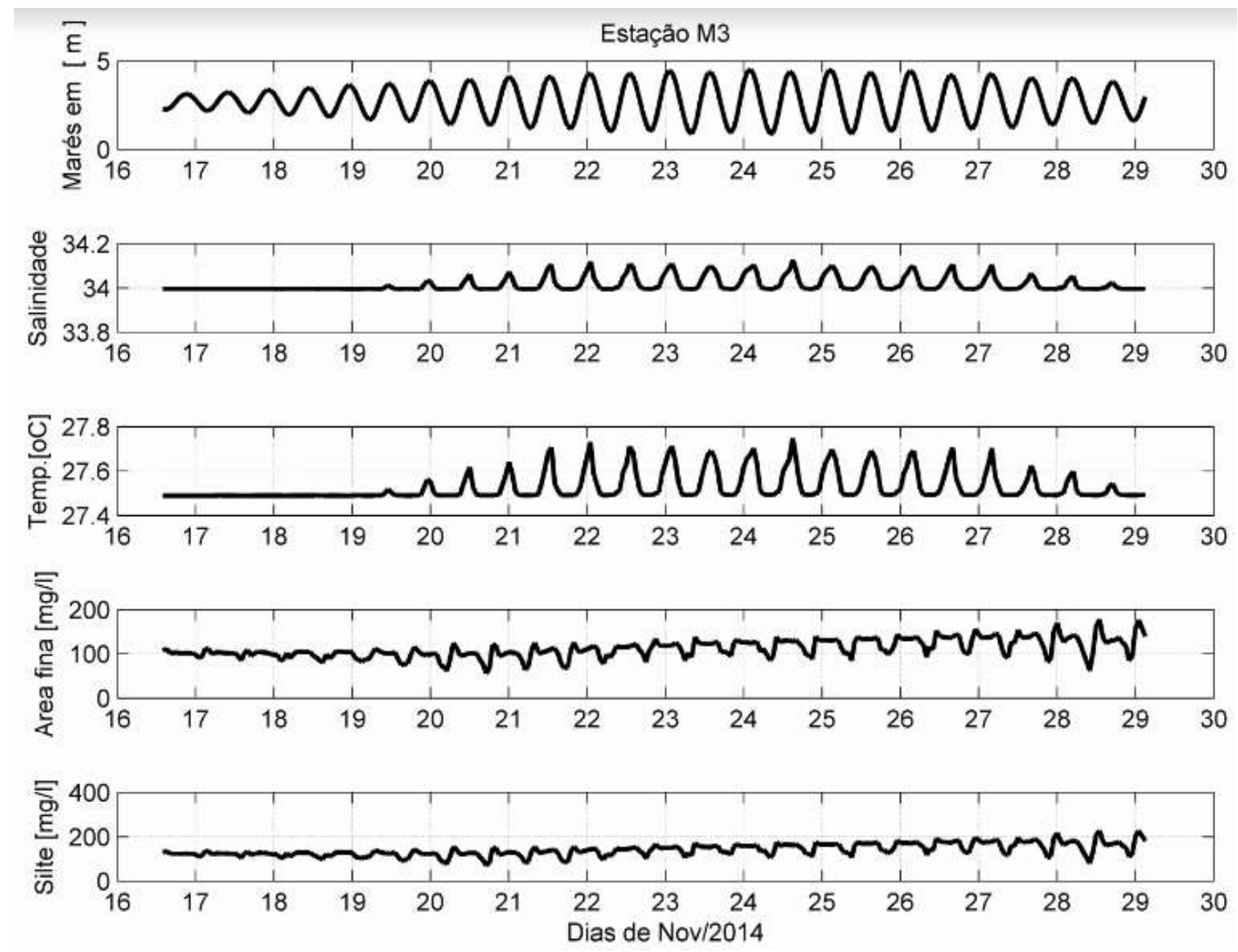

Figura 8 - Série temporal da temperatura, salinidade, marés, silte e areia fina na confluência (M5). 
$\mathrm{Na}$ Figura 9 são apresentados resultados referentes a estação M3, escolhida propositadamente para análise de sedimentos suspensos na zona proposta para a construção e reabilitação do porto de Macuse. A salinidade variou entre 34 e 34,2 que é relativamente maior que da estação M5, enquanto a temperatura variou entre $27,4^{\circ} \mathrm{C}$ e $27,8^{\circ} \mathrm{C}$. Os sedimentos suspensos mostraram forte dependência da elevação das marés, variando entre 100 mg/l e 200 mg/l para areia fina, e entre 150 e $200 \mathrm{mg} / \mathrm{l}$ para silte. Essas concentrações são menores que as observadas na estação M5, explicando um possível assoreamento de sedimentos no leito antes da estação M3, por gravidade devido ao seu peso e falta de energia hidráulica suficiente para transportar os sedimentos em suspensão na lâmina da água e por arrasto no fundo do leito rio. Esses processos também foram observados por SCHETTINI et al. (2003), SHI et. al. (2003) e CHEN et al. (2015) em ambientes similares no Brasil e na China. De fato, esse comportamento indica que estação M3 é relativamente menos afetada por sedimentos provenientes dos afluentes de Namacurra e afluente direito, o que sugere menos impacto negativo nas atividades técnicas operacionais do porto.
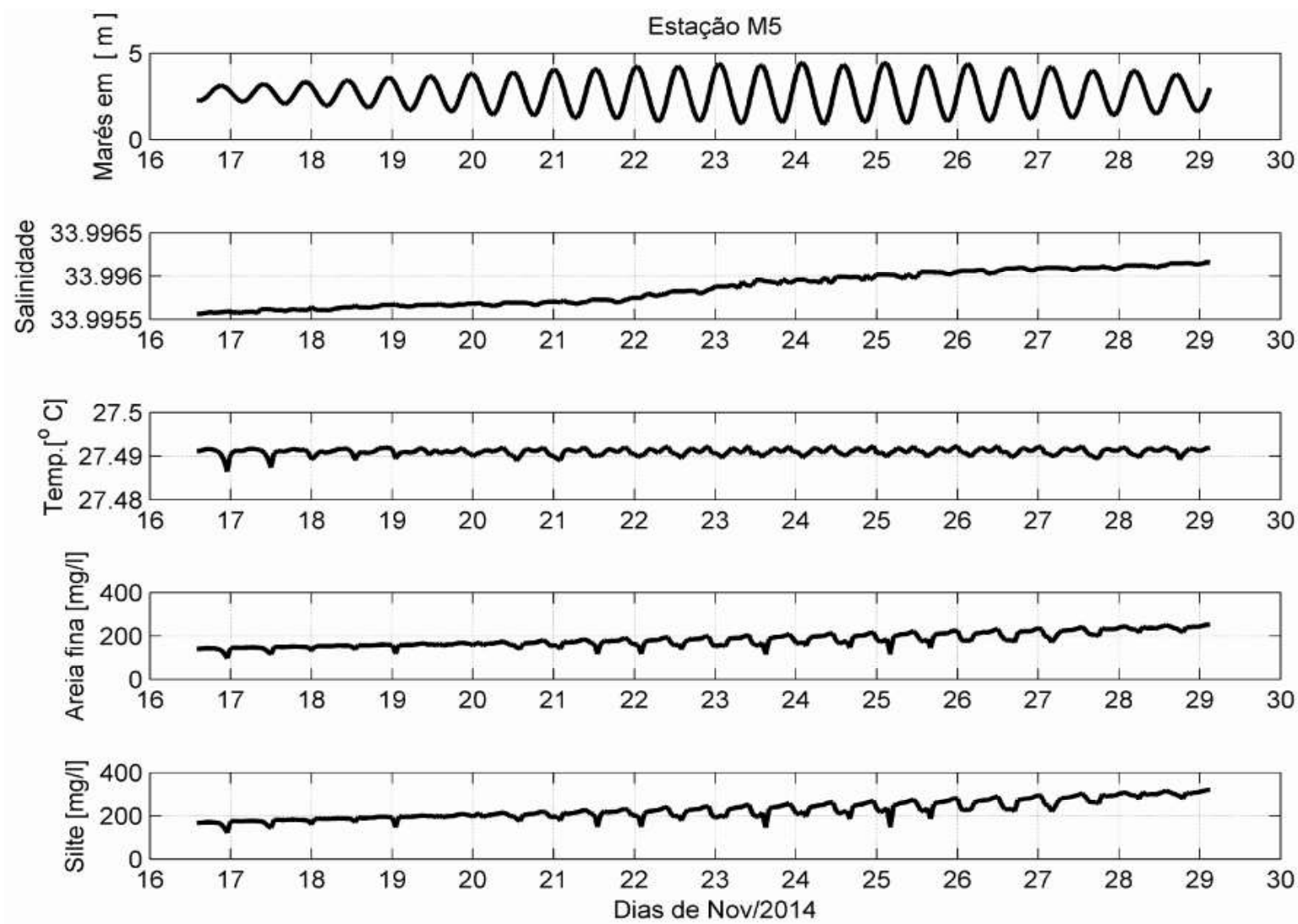

Figura 9 - Séries temporais da Temperatura, Salinidade, Marés, silte e areia fina na Porto (M3).

A Estão M1 foi escolhida para entender o comportamento dos sedimentos em suspensão, a dinâmica morfológica e a variação dos parâmetros físicos na desembocadura do estuário. A salinidade ilustrada na Figura 10 (M1) indica um máximo de 35 na enchente da maré de sizígia, indicativo da sua dependência da elevação da maré. Este valor mostra ser o maior quando comparado com as estações M5 (confluência) e M3 (estação do porto de Macuse). É evidente a sua contribuição como a fonte de água salgada que distribui-se espacialmente ao longo do estuário em função das marés associada a ventos, rugosidade e volumes de água doce da jusante. Apesar de a temperatura não variar de forma significativa no período em análise, o seu máximo foi observado na maré de quadratura com $27,8^{\circ} \mathrm{C}$. A concentração de sedimentos indicou uma variação entre $60 \mathrm{mg} / \mathrm{l}$ e $150 \mathrm{mg} / \mathrm{l}$ de areia fina e entre 100 e $200 \mathrm{mg} / \mathrm{l}$ para silte. Essas concentrações variaram conforme a elevação da maré e são relativamente inferiores que as observadas na s estações M5 e M3. Essa diferença é explicada pelo fato da sua localização ser distante da fonte de sedimentos provenientes dos rios, em que o seu incremento nas concentrações da lâmina de água é realizado pelo processo de ressuspensão devido a ação de marés na desembocadura. 

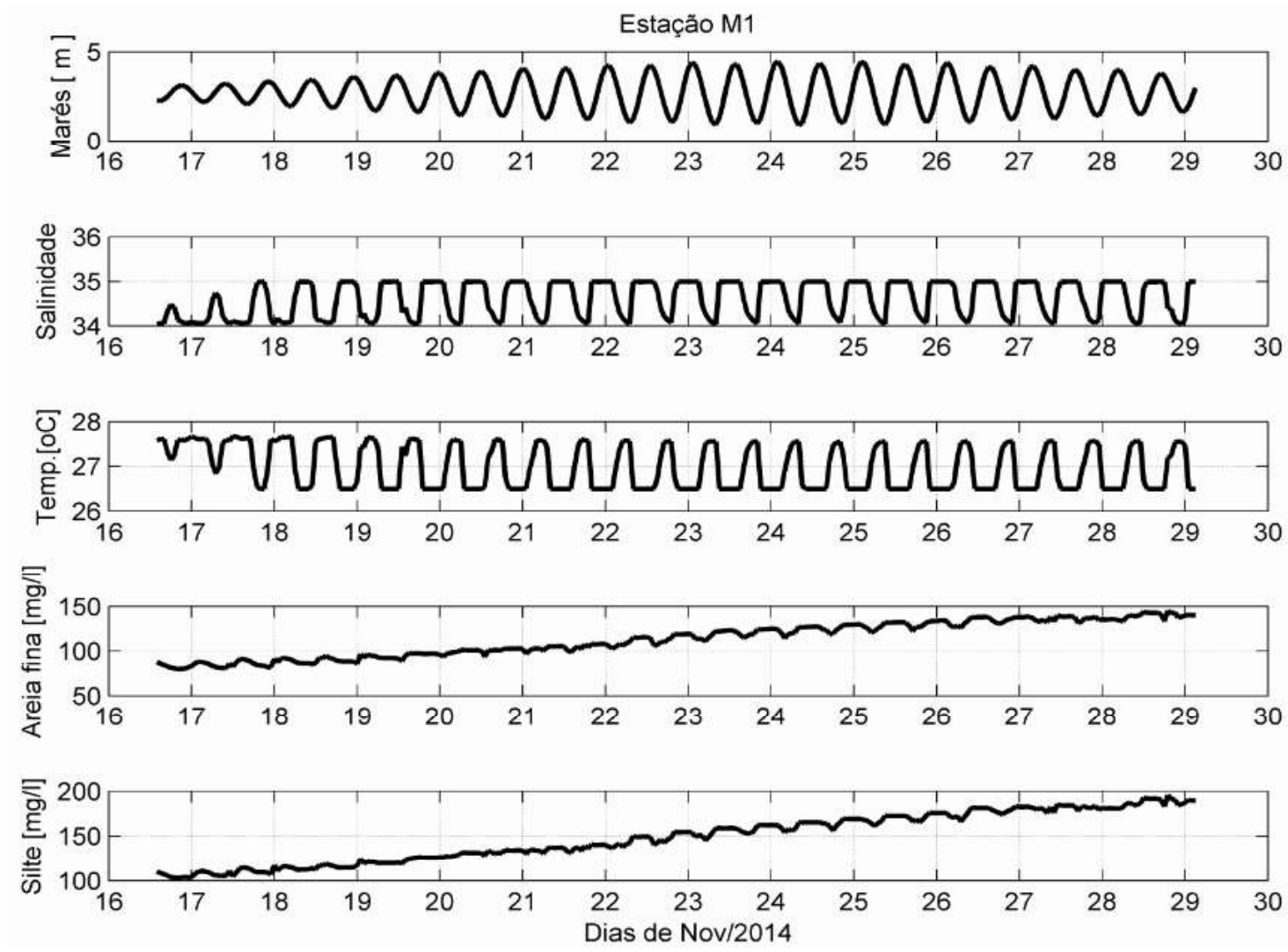

Figura 10 - Série temporal da Temperatura, Salinidade, Marés e Sedimentos finos e grossos na desembocadura (M1).

Na Figura 11 são apresentados na secção longitudinal resultados observados em campo, da clorofila-a (a) e turbidez (b) da água. Estes resultados auxiliam a interpretação do material particulado suspenso na coluna da água, independente da sua composição mineralógica ou biológica. A análise de refletância do material particulado na lâmina da água indicou 12 e $14 \mu \mathrm{g} / 1$ na zona da confluência e na desembocadura do Rio Namacurra, enquanto a clorofila-a (Figura 11- a) mostrou valores elevados na zona intermediaria do leito do rio indicando valores entre $0,05 \mu \mathrm{g} / \mathrm{l}$ e 0,3 $\mu \mathrm{g} / \mathrm{l}$. Essa concentração sugere que a zona intermediaria, onde encontra-se a estação M3, e pode ser considerada como a zona óptima de acomodação da matéria orgânica suspensa ou particulada com propriedades orgânicas. Essa acumulação pode obstruir a penetração da luz na lâmina da água (BOWERS et al., 2004), diminuindo a produção de elementos essenciais a biota, porém criando condições de sedimentação o que diminui a profundidade do leito do canal. A turbidez mostrou valores relativamente altos na desembocadura com cerca de 160 NTU e 120 NTU na confluência. Este comportamento na desembocadura do estuário, mostra analiticamente a influência das marés combinadas com o regime de ventos, a rugosidade do fundo, a velocidade da água na ressuspensão de sedimentos do leito. Enquanto na zona da confluência, o fator principal é a fonte de sedimentos proveniente dos afluentes que alimenta material particulado nos períodos de grandes volumes de água na estação chuvosa.

A turbidez da água comporta-se como correntes de densidade na coluna de água estratificada (FISHER et al.,1979; IMBERGER e PATTERSON, 1990). Este fato é testemunhado na Figura 11 b), onde está evidente a suspensão de sedimentos que entram no estuário forçadas pela maior energia de marés na desembocadura. Enquanto as descargas fluviais são responsáveis no transporte da frente da pluma de sedimentos do Rio Namacurra para a confluência até a desembocadura. Fator importante nesta análise, é a relação da mistura da água e os sedimentos suspensos que requer segundo IMBERGER \& HAMBLIN (1982) e MALKI-EPSHTEIN et al., (2004), uma relação constitutiva dependente da fração do tamanho dos sedimentos suspensos e das características físico-químicas, porque podem exibir duplas feições difusivas. 

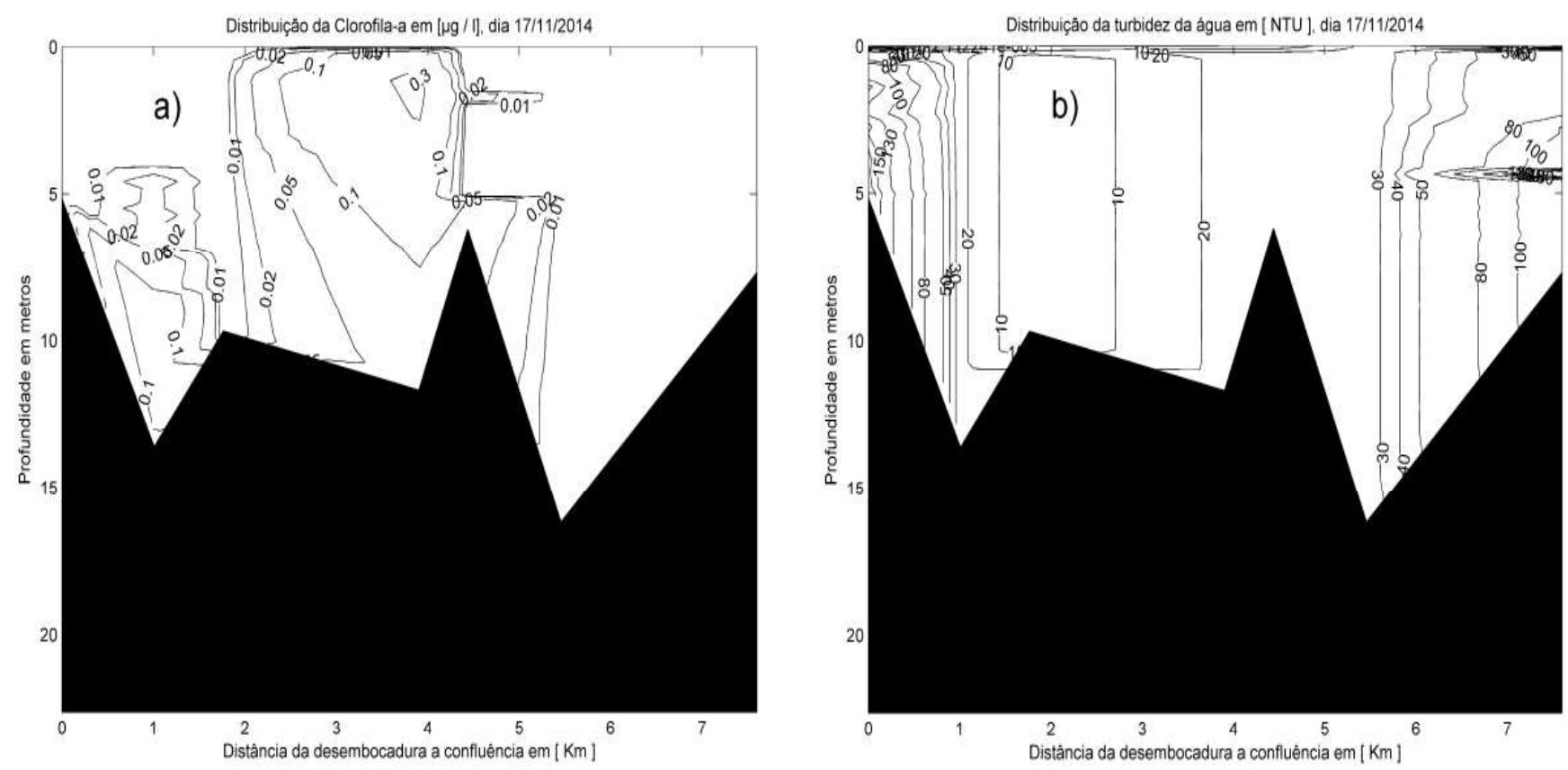

Figura 11 - Secção longitudinal de resultados observados in situ da clorofila-a (a) e turbidez (b) da água.

Integrando os resultados das estações M1, M3 e M5, observa-se uma dinâmica complexa de sedimentos suspensos provenientes dos seus afluentes, principalmente do rio Namacurra. Sua dependência ao regime de marés e descargas dos rios Namacurra e tributários associados, mostrou uma boa concordância com resultados observados e discutidos por DALRYMPLE et. al. (1995) nas mesmas condições hidrodinâmicas. Os sedimentos suspensos encontrados no Rio Macuse no período em estudo, tem sua fonte principal o afluente de Namacurra e o afluente direito, com indicação de fonte resultante de ressuspensão na desembocadura do estuário. Tais sedimentos são transportados pela circulação gravitacional estuarina e assimetria de marés, que segundo SHI et al. (2004a) são de grande importância no processo de transporte em suspensão de sedimentos finos e matéria orgânica particulada nesses ambientes. Essa afirmativa corrobora com os resultados da hidrodinâmica de marés do estuário do Rio Macuse, que desatacou-se como fator determinante no transporte de sedimentos suspensos e ressuspensão de material do fundo do leito. Na mesma perspectiva, SHI (2010) observou que o padrão complexo de fluxo de interação da circulação gravitacional estuarina e assimetria de marés é largamente determinante quando interagem com as descargas fluviais, correntes de marés e variação de geomorfologia do leito $\mathrm{e}$, igualmente influenciada pelas diferenças de densidade, regime de ventos e força de Coriolis. A pesar da localização distinta, os resultados deste estudo, concordam veemente com o efeito dos fatores identificados por SHI (2010).
Observou-se de forma persistente, o transporte de sedimentos do grupo de silte e do grupo de areia fina (na escala de WENTWORTH,1922a) pela pluma de água proveniente de montante para a desembocadura do Rio Macuse. O processo de deposição ou ressuspensão dessa carga sedimentar suspensa indicou forte relação com a variação das correntes de marés, ciclicamente de enchente a vazante ou vice-versa. Assim, a sedimentação ou deposição de sedimentos suspensos no estuário de Macuse depende da velocidade de deposição estimada em $10 \mathrm{~cm} / \mathrm{s}$ para o grupo de areia fina e $0,1 \mathrm{~cm} / \mathrm{s}$ para silte. A deposição é um processo que segundo SHI \& ZHOU (2004) é dependente da ordem hidrodinâmica, salinidade, processos de floculação, forca do floco, estrutura fractal, concentração de sedimentos, composição de sedimentos, e o tempo de residência dos flocos. Apesar de não se analisar todos esses fatores, os resultados desta pesquisa corroboram especificamente com a hidrodinâmica, concentração, composição de sedimentos e tempo de residência.

A taxa residual desses processos não foi analisada, porém, vários parâmetros físicos analisados neste trabalho mostraram-se que o estuário de Macuse é governado por correntes residuais em direção a desembocadura. Esse comportamento hidráulico corrobora com os resultados obtidos em outros estuários do mundo (SCHETTINI et al., 2003; SHI et. al., 2003 e CHEN et al., 2015). De fato, os resultados obtidos indicaram que as areias finas depositaram-se rapidamente nos limites da pluma fluvial em consequência do seu peso, viscosidade, gravidade, a densidade e a rugosidade do fundo. Por outro lado, os 
sedimentos mais finos do grupo silte são transportados por significativas longas distâncias em decorrente do seu pequeno peso e volume. A par desta observação, testemunhado pela Figura $7 \mathrm{e} 11$ e por HURZELER et al. (1994, 1995), a deposição de sedimentos suspensos mudou de forma efetiva a flutuação da densidade do fluxo de entrada, mudando o fluxo de fundo para superfície a uma distância relativamente pequena. Essa dinâmica estuarina de material particulado, pode ser transportada facilmente a distâncias relativamente maiores quando o leito ou perfil geomorfológico é acentuado para a desembocadura do estuário. Tal afirmação é concordante com MORGAN (1980) e por HADLEY et al. (1985), quando afirmaram em seus estudos que, o acréscimo na declividade contribui para o aumento na velocidade do escoamento superficial e sua capacidade de erosão. Desta forma, a carga suspensa percorre vários metros por processos de salteamento ou arrastamento por meio hidráulico. Esses processos esculpem o material disponível tornando mais fino e mais arredondado quanto maior for a distância de arrastamento.

A análise residual de sedimentos suspensos mostrou um saldo positivo de montante a desembocadura, governados pela direção, sentido e da intensidade das correntes que são extremante conectados com o perfil geomorfológico do canal que aumenta a declividade. Apesar das diferenças de condições climáticas, geológicas e de localização geográfica, os resultados observados no Rio Macuse, mostraram certa similaridade com os obtidos em outros locais do mundo como os observados no estudo de DYER (1995 e 1988), em um ambiente estuarino característico de Macuse.

A dissipação de energia na desembocadura do estuário mobiliza os sedimentos colocando-os em suspensão (MANTOVANELLI, 1999; FERNANDES, 2001 e LIMA, 2001). Este comportamento foi característico e evidente no estuário de Macuse (Figura 10). Nessa perspectiva, foram observadas grandes quantidades frações de sedimentos suspensos nos períodos das marés enchentes e de sizígia. SHI et al. (2003) e SHI e ZHOU (2004) observaram que a estratificação da água torna os sedimentos suspensos mais tempo na coluna da água, apesar de não ser alvo deste estudo, este processo não foi muito evidente. Porém as variações cíclicas da salinidade nos períodos da maré de sizígia e de quadratura, terão mantido os sedimentos suspensos na lâmina da água por mais tempo.

\section{Considerações finais}

Os resultados in situ e modelados indicaram marés $\mathrm{de}+4,0 \mathrm{~m}$ que geraram correntes de marés entre $-0,8 \mathrm{~m} / \mathrm{s}$ e $+1,2 \mathrm{~m} / \mathrm{s}$. Seu regime hidrodinâmico cíclico definiu a mecânica do transporte de sedimentos em suspensão do grupo de silte e areia fina por arrasto. Esses sedimentos são provenientes dos seus afluentes, com mais destaque do afluente do Rio Namacurra, seguido pelo afluente direito e a desembocadura com o mar. O seu transporte tem seu vetor principal às ondulações causadas pelas marés provenientes do Oceano Indico e as descargas fluviais sazonais dos seus afluentes.

A hidrodinâmica combinada com a geomorfologia do leito do estuário do Rio Macuse, mostraram-se responsáveis na deposição e ressuspensão da carga sedimentar da lâmina da água. Suas concentrações sugerem a ocorrência de sedimentação e assoreamento no leito do Rio Macuse com fluxo inferior a $0,01 \mathrm{~cm} / \mathrm{s}$ de silte e com fluxo inferior a $10 \mathrm{~cm} / \mathrm{s}$ para a areia muito fina. Os sedimentos mais finos do grupo de silte foram transportados por longas distâncias significativas explicadas pelo seu baixo valor de deposição, enquanto que o processo de deposição da areia muito fina foi realizado por arrasto nos limites da pluma fluvial sob efeito do seu peso, viscosidade, gravidade, a densidade e a rugosidade do fundo. Desta forma, verificou-se que a taxa residual dos sedimentos é de montante a jusante acompanhada pela dissipação de maior energia na zona da desembocadura, que mobiliza os sedimentos do fundo colocando-os em suspensão.

Os sedimentos simulados mostraram frações de concentrações sedimentares dependentes da periodicidade das correntes de marés, da variação da batimetria, e da proximidade da área fonte. Os valores máximos de concentração de sedimentos suspensos foram observados na vazante e no período de maré de sizígia entre $100 \mathrm{mg} / 1$ e $300 \mathrm{mg} / 1$ para silte e areia muito fina. Sua distribuição espacial foi definida em função da corrente de marés inferiores a velocidade crítica de $10 \mathrm{~cm} / \mathrm{s}$ e $0,1 \mathrm{~cm} / \mathrm{s}$, o que sugeriu locais de ocorrência de deposição de sedimentos suspensos na lâmina da água que causam modificações significativas na configuração geomorfológica do leito, e que podem influenciar sobremaneira as operações portuárias.

\section{Agradecimentos}

Este estudo foi financiado pelo Ministério de Ciência e Tecnologia de Moçambique, em cooperação com a Universidade Eduardo Mondlane na aquisição dos dados de campo. Agradecimento especial vai para a Universidade Federal do Rio de Janeiro, Programa de Pós-graduação em Geologia, em especial ao Museu Nacional - UFRJ. A empresa sul-africana de consultoria $L W A N D L E$ que tornou possível a coleta de dados de 2014, e ao Senhor Moniz Tito, estudante da Universidade Eduardo Mondlane pela assistência prestada no trabalho de campo. 


\section{Referências Bibliográficas}

AAGAARD, T., GREENWOOD, B.; NIELSEN, J. Mean currents and sediment transport in a rip channel. Marine Geology, v.140, p. 25-45, 1997.

BIAZIN, P. C.; SANTOS, M. L; Características geomórficas do canal e das formas de leito do rio Ivaí em seu curso inferior, Icaraíma- pr. Revista brasileira de geomorfologia - ano 9, $\mathrm{n}^{\mathrm{0}}$ 1, 2008.

BIGGS, R.B. Sources and distributions of suspended sediments in Northern Chesapeake Bay. Marine Geology. v.9, p.87-201, 1970.

BOWERS, D., EVANS, D., THOMAS, D., ELLIS, K., WILLIAMS, P. Interpreting the colour of an estuary. Estuar. Coast. Shelf Sci. v.59, p.13-20, 2004.

CHEN, S. L., ZHANG, G., YANG, S., SHI, J.Z.. Temporal variations of fine suspended sediment concentration in the Changjiang River estuary and adjacent coastal Waters. China. Journal of Hydrology. v.331, p.137-145, 2006. doi:10.1016/j.jhydrol.2006.05.013

CHEN, W.; LIU, W.; HSU, M., HWANG, C. Modelling investigation of suspended sediment transport in a tidal estuary using a three-dimensional model. Applied Mathematical Modelling . Volume 39, Issue 9, p.2570-2586.2015.http://dx.doi.org/10.1016/j. apm.2014.11.006.

COOPER, J.A.G. The role of extreme floods in estuary-coastal behaviour: contrasts between river- and tide-dominated microtidal estuaries. Sedimentary Geology 150 (2002) 123-137. 2001

D’Aquino, C. A. Processos de transporte e retenção de sedimentos finos em estuários dominados por rios. Tese de Doutorado. UFRGS. Porto Alegre. 2010

DALRYMPLE, R.W., RHODES, R.N. Estuaries dunes and bars. In:Perillo,G.M.E. (Ed.), Geomorphology and Sedimentology of Estuaries, Developmentsin Sedimentology. Amstedam, the Netherlands, p.359-422, 1995.

DELOFFRE, J., LAFITE, R., LESUEUR, P., VERNEY, R., LESOURD, S., CUVILLIEZ, A., TAYLOR, J. Controlling factors of rhythmic sedimentation processes on an intertidal estuarine mudflat-role of the turbidity maximum in the macrotidal Seine estuary, France. Mar. Geol. v.235, p.151-164, 2006.

DYER K.R. Coastal and Estuarine Sediment Transport. A Wiley. Interscience Publication. Institute of Oceanographic Sciences. Bidston, UK. p.342, 1988.

DYER, K.R. Sediment Transport Processes in Estuaries. In: Perillo, G. M. E. (ed). Geomorphology and Sedimentology of Estuaries. Developments in Sedimentology ,v.53,p. 423-449,1995.

EDWARDS, L.; BURNEY, J.; BRIMACOMBE, M. \& MACRAE, A. Nitrogen runoff in a potato-dominated watershed area of Prince
Edward Island, Canada. In: Stone, M. (Editor). The role of erosion and sediment transport in nutrient and contaminant, 2000.

ERIKSON, L. H.; WRIGHT, S.A.; ELIAS, E.; HANES, D. M.; SCHOELLHAMER, D.H.; LARGIER, J. The use of modeling and suspended sediment concentration measurements for quantifying net suspended sediment transport through a large tidally dominated inlet . USA, 2013.

FAIN, A.M.V., JAY, D.A., WILSON, D.J., ORTON, P.M., BAPTISTA, A.M. Seasonal and tidal monthly patterns of particulate matter dynamics in the Columbia River estuary. Estuaries. v.24,nº 5, p. $770-786,2001$.

Fernandes, L.D.F. Transporte de Poluentes em Estuários. Trabalho de Final de Curso da Licenciatura em Engenharia do Ambiente. Universidade Técnica de Lisboa, Lisboa.p.40,2001.

FIGUEIREDO, S.A. \& CALLIARI, L.J. Sedimentologia e suas Implicações na Morfodinâmica das Praias Adjacentes às Desembocaduras da Linha de Costa do Rio Grande do Sul. Gravel. v. 4, p.73-87,2006.

FISCHER, H.B., LIST, E.J., KOH, R., IMBERGER, J., BROOKS, N.H. Mixing in Inland and Coastal Waters. Academic Press, New York, NY., 1979.

GELFENBAUM, G. Suspended-sediment response to semidiurnal and fortnightly tidal variations in a mesotidal estuary: Columbia River, USA. Marine Geology.v.52, p.39-57, 1983.

GRABEMANN, I., KRAUSE, G. On different time scales of suspended matter dynamics in the Weser Estuary. Estuaries. v.24, p.688-698, 2001.

HADLEY, R. F. Recent development in erosion and sediment yield studies. Paris: United Nations Educational Scientific and cultural Organization-Unesco, p.127, 1985.

HURZELER, B.E., IVEY, G.N., IMBERGER, J. Spreading model for a turbidity current with reversing buoyancy from a constantvolume release. Mar. Freshw. Res. v.46,v.393-408, 1995.

IMBERGER, J., HAMBLIN, B. Dynamics of lakes, reservoirs, and cooling ponds. Ann. Rev. Fluid Mech.v.14, p.153-187, 1982.

IMBERGER, J., PATTERSON, J.C. Physical limnology. In: Wu, T. (Ed.), Advances in Applied Mechanics, v. 27, p. 302-475, 1990. INSTITUTONACIONALDEHIDROGRAFIADENAVEGAÇÃO (INAHINA) DE MOÇAMBIQUE. Tabela de marés de 2015. 2015.

JENSEN, J. H.; MADSEN, E. E. FREDSOE, J. Oblique Flow Over Dredged Channels. I: Flow description. Journal of Hydraulic Engineering, Lyngby, Dinamarca.v.125, p.1181-1189, 1999.

KITHEKA, J.U.,OBIERO M., NTHENGE P. River discharge, sediment transport and exchange in the Tana Estuary, Kenya, 2005 . 
KNIGHTON, D. Fluvial forms and processes: a new perspective. London: Arnold, p.382, 1998.

LIMA, G. M. P.; LESSA, G. C. The Fresh-Water Discharge in Santos Bay $(\mathrm{Ba})$ and its Significance to the General Water Circulation. Revista de Pesquisas em Geociências, v.28, n²0, p.85-96, 2001.

LUO, J.; LI, M., SUN, Z.; O’CONNOR, B. A. Numerical modelling of hydrodynamics and sand transport in the tidedominated coastal-to-estuarine region. China, 2013.

MALKI-EPSHTEIN, L., PHILLIPS, O.M., HUPPERT, H. The growth and structure of double-diffusive cells adjacent to a cooled sidewall in a salt-stratified environment. J. Fluid Mech. v.518, p.347-362, 2004.

MANTOVANELLI, A. Caracterização da dinâmica hídrica e do material particulado em suspensão na Baia de Paranaguá e em sua bacia de drenagem. Dissertação de Mestrado. UFPR, Dept.Geologia. p.152,1999.

Ministério Da Planificação E Desenvolvimento. Diagnóstico Preliminar E Acções De Reconstrução Pós-Calamidades de 2013. República De Moçambique. Maputo, Março De 2013.2013.

MOREIRA, M.E. A dinâmica de sistemas litorais do sul de Moçambique durante os últimos trinta anos. Finisterra, XI,v.79, p. $121-135,2005$.

MORGAN, R. P. C. (Ed.). Soil erosion. Chichester, Cambridge: John Wiley and Sons. p.109-129.1980.

NEHAMA, FIALHO. P. J. Modelling the Zambezi River plume using the Regional Oceanic Modelling System. Thesis presented for the Degree of Doctor of Philosophy. Oceanography Department, Faculty of Science, University of Cape Town, South Africa. p.177, 2012.

PATCHINEELAM, S.M., KJERFVE, B. Suspended sediment variability on seasonal and tidal time scales in the Winyah Bayestuary, South Carolina, USA. Estuarine, Coastal and Shelf Science. v.59,p.307-318,2004.

RAMSAY,P.J. AND COOPER,J.A.G. Late Quaternary sea level changes in Southern Africa. Quaternary Research. v.57, p.8290, 2002.

RAO, V. P. ; SHYNU, R. ; KESSARKAR, P. M. ; SUNDAR, D. ; MICHAEL, G.S. ; NARVEKAR, T.; BLOSSOM, VI.; MEHRA, $P$. Suspended sediment dynamics on a seasonal scale in the Mandovi and Zuar estuaries, Central west Coast of India. National Institute of Oceanography, CSIR, Dona Paula 403 004, Goa, India, 2011

ROSA, R.M. Estudo doefeito das descargas de nutrientes no reservatório APM-Manso: uma abordagem através da modelagem numérica tridimensional. 189f,2010.

SCHETTINI, A. C. A. Estudo do regime de corrrentes e material particulado em suspensão ao largo do estuário do rio itajaí-açu. II Congresso sobre Planejamento e Gestão das Zonas Costeiras dos Países de Expressão Portuguesa IX Congresso da Associação Brasileira de Estudos do Quaternário II Congresso do Quaternário dos Países de Língua Ibéricas. Brasil, 2003.

SHI, J.Z. Tidal resuspension and transport processes of fine sediment within the river plume in the partially-mixed Changjiang River estuary, China: A personal perspective. Geomorphology.v.121,p.133-151, 2010.

SHI, Z. Behaviour of fine suspended sediment at the North Passage of the Changjiang Estuary, China. Journal of Hydrology.v.293,p.180-190,2004a.

SHI, Z., KIRBY, R. Observations of fine suspended sediment processes in the turbidity maximum at the North Passage of the Changjiang Estuary, China. Journal of Coastal Research.v.19.n³,p.529-540, 2003.

SHI, Z., ZHOU, H.J. Controls on settling velocities of mud flocs in the Changjiang Estuary, China. Hydrological Processes.v.18,nº15,p.2877-2892,2004.doi:10.1002/hyp.102.

SIMONS, D. B.; RICHARDSON, E. V. Physiografhic and hidraulic atudies of rivers: resistance to flow in alluvial channel. Washington: Geol.Surv.Prof. Pap, 1966

SOULSBY, R.L. The bottom boundary layer of shelf seas. In: John, B. (Ed.), Physical Oceanography of Coastal and Shelf Seas. Elsevier Science Publishers, Amsterdam. Talke, S.A., Stacey,M.T., 2008. Suspended sediment fluxes at an intertidal flat: the shifting influence of wave, wind, tidal, and freshwater forcing. Cont. Shelf Res. v.28.nº, p.710-725,1983.

STONE \& HAIGHT. Distribution of dioxins and furans in size-fractioned suspend solids in Canagagigue Creek, Elmira, Ontario. In: Stone, M.(Editor). The role of erosion and sediment transport in nutrient and contaminant transfer. IAHS Publication.v.263,p.93-97, 2000.

YANG, S.L.; SHI, J.Z. Temporal variations of fine suspended sediment concentration in the Changjiang River estuary and adjacent coastal waters. Journal of Hydrology, 2006. doi:10.1016/j.jhydrol.2006.05.013

YOSHIKAWA, S.; NEMOTO, K. Seasonal variations of sediment transport to a canyon and coastal erosion along the Shimizu coast, Suruga Bay, Japan. Coastal geomorphology. SAGE Journals, v.19, 2010. 